\title{
Autoimmune Thyroid Disease Correlates to Islet Autoimmunity on Zinc Transporter 8 Autoantibody: A Cross-Section Study
}

\section{Yun Cai}

Department of Endocrinology, The First Affiliated Hospital of Nanjing Medical University, Nanjing, Jiangsu, China

\section{Jieni Yan}

Department of Endocrinology, The First Affiliated Hospital of Nanjing Medical University, Nanjing, Jiangsu, China

\section{Yong Gu}

Department of Endocrinology, The First Affiliated Hospital of Nanjing Medical University, Nanjing, Jiangsu, China

\section{Heng Chen}

Department of Endocrinology, The First Affiliated Hospital of Nanjing Medical University, Nanjing, Jiangsu, China

\section{Qingfang Hu}

Department of Endocrinology, The First Affiliated Hospital of Nanjing Medical University, Nanjing, Jiangsu, China

\section{Yang Chen}

Department of Endocrinology, The First Affiliated Hospital of Nanjing Medical University, Nanjing, Jiangsu, China

\section{Zhixiao Wang}

Department of Endocrinology, The First Affiliated Hospital of Nanjing Medical University, Nanjing, Jiangsu, China

\section{Xiaoyun Liu}

Department of Endocrinology, The First Affiliated Hospital of Nanjing Medical University, Nanjing, Jiangsu, China

\section{Huanhuan Chen}

Department of Endocrinology, The First Affiliated Hospital of Nanjing Medical University, Nanjing, Jiangsu, China

\section{Xinyu Xu}

Department of Endocrinology, The First Affiliated Hospital of Nanjing Medical University, Nanjing, Jiangsu, China

\section{Mei Zhang}


Department of Endocrinology, The First Affiliated Hospital of Nanjing Medical University, Nanjing, Jiangsu, China

\section{Liping Yu}

Barbara Davis Center for Childhood Diabetes, University of Colorado Denver, Aurora, CO, USA

\section{Xuqin Zheng}

Department of Endocrinology, The First Affiliated Hospital of Nanjing Medical University, Nanjing, Jiangsu, China

\section{Tao Yang ( $\nabla$ yangt@njmu.edu.cn )}

the first affiliated hospital of nanjing medical university https://orcid.org/0000-0001-6375-3622

\section{Research}

Keywords: autoimmune thyroid disease, type 1 diabetes mellitus, zinc transporter 8 autoantibody, thyroid peroxidase autoantibodies

Posted Date: August 19th, 2020

DOI: https://doi.org/10.21203/rs.3.rs-60065/v1

License: (c) (i) This work is licensed under a Creative Commons Attribution 4.0 International License. Read Full License 
1 Title page

\section{Autoimmune Thyroid Disease Correlates to Islet Autoimmunity on Zinc Transporter 8} Autoantibody : A Cross-section Study

4

5 Yun $\mathrm{Cai}^{{ }^{*}}{ }^{*}$, Jieni $\mathrm{Yan}^{1}{ }^{*}$, Yong $\mathrm{Gu}^{1}$, Heng $\mathrm{Chen}^{1}$, Qingfang $\mathrm{Hu}^{1}$, Yang Chen ${ }^{1}$, Zhixiao Wang ${ }^{1}$,

6 Xiaoyun $\mathrm{Liu}^{1}$, Huanhuan $\mathrm{Chen}^{1}$, Xinyu $\mathrm{Xu}^{1}$, Mei Zhang ${ }^{1}$,Liping $\mathrm{Yu}^{2}$, Xuqin Zheng ${ }^{1 \Delta}$, Tao

$7 \quad \operatorname{Yang}^{1 \Delta}$

8

91 Department of Endocrinology, The First Affiliated Hospital of Nanjing Medical University,

$10 \quad$ Nanjing, Jiangsu, China;

112 Barbara Davis Center for Childhood Diabetes, University of Colorado Denver, Aurora, CO, 12 USA.

$13 *$ These authors contributed equally to this work.

${ }^{\Delta}$ Corresponding author and person to whom reprint requests should be addressed:

15 Xuqin Zheng, E-mail: zhengxuqin@njmu.edu.cn

16 Tao Yang, E-mail: yangt@njmu.edu.cn

17 Department of Endocrinology, the First Affiliated Hospital of Nanjing Medical University, 300 Guangzhou Road, Nanjing, 210029, Jiangsu, China 


\section{Abstract}

3 Background: The most common coexisting organ-specific autoimmune disease in patients

4 with Type 1 diabetes mellitus (T1DM) is autoimmune thyroid disease (AITD). Many studies

5 have showed prevalence rate of thyroid autoantibodies range from 3.7-35\% in T1DM patients,

6 while some of them suggested the associations between thyroid autoantibodies and islet

7 autoantibodies. However, little work has been done about the anti-islet autoimmune status in

8 patients with autoimmune thyroid disease (AITD), and so far there have been no clinical

9 report based on large population about zinc transporter 8 autoantibody (ZnT8A) in patients

with AITD. We aimed to explore the presence of islet autoantibodies, ZnT8A, glutamic acid decarboxylase autoantibodies (GADA) and tyrosine phosphatase autoantibodies (IA-2A) compared with thyroid autoantibodies, thyroid peroxidase autoantibodies (TPOAb) and thyroglobulin autoantibodies (TGAb) and thyrotropin receptor autoantibodies (TRAb) in

14 AITD patients.

Methods: In total 740 AITD patients, 108 type 1 diabetes mellitus (T1DM) patients with AITD, 172 non-autoimmune thyroid disease (nAITD) patients and 115 healthy controls were recruited in the cross-sectional study. Islet autoantibodies, ZnT8A, GADA, IA-2A and thyroid autoantibodies, TPOAb, TGAb, TRAb were detected with Radioimmunoassay and

19 Chemiluminescence. Islet autoantibody relative value was established to compare the distribution of the three islet autoantibodies.

Results: The prevalence of ZnT8A and GADA in AITD group was significantly higher than that in healthy controls (ZnT8A: $15.00 \%$ vs $1.74 \%$, GADA: $7.97 \%$ vs $0.87 \%$, both $\mathrm{P}<0.05$ ). Similarly, the prevalence of IA-2A in AITD group was higher than that in healthy controls (4.19\% vs $0 \%, \mathrm{P}<0.05)$. However, any islet autoantibodies positive rate in AITD group was significantly lower than that in T1DM with AITD group. Analysis of multivariable linear 
regression suggested that ZnT8A relative value was positively related with GADA relative value $(\beta=0.352, \mathrm{P}<0.01)$ and TPOAb titer $(\beta=0.002, \mathrm{P}<0.01)$, and GADA relative value was also positively related with $\mathrm{ZnT} 8 \mathrm{~A}$ relative value $(\beta=0.183, \mathrm{P}<0.01)$.

Conclusions: An increased prevalence of ZnT8A as well as a relatively high prevalence of islet autoimmunity was found in AITD patients, indicating that there is a potential link between thyroid autoimmunity and islet autoimmunity.

Trial registration: Retrospectively registered.

\section{Keywords}

autoimmune thyroid disease, type 1 diabetes mellitus, zinc transporter 8 autoantibody, thyroid peroxidase autoantibodies

\section{Background}

Autoimmune thyroid disease (AITD) is a common organ-specific autoimmune disorder which includes two main clinical presentations: Graves' disease and Hashimoto's thyroiditis. Both Graves' disease and Hashimoto's thyroiditis share the immunologic feature of the presence of circulating autoantibodies such as thyrotropin receptor autoantibodies (TRAb), thyroid peroxidase autoantibodies (TPOAb) and thyroglobulin autoantibodies (TGAb). TRAb occur predominantly in Graves' disease and play a key role in Graves' hyperthyroidism, while TGAb and TPOAb are found more frequently in Hashimoto's thyroiditis, and the latter tend to correlate with thyroidal damage and lymphocytic inflammation $(1,2)$.

Individuals with AITD may be associated with other autoimmune diseases, of which type 1 diabetes mellitus (T1DM) is the most frequent(3-5) . An increased risk of T1DM was reported in patients with AITD, the phenotype is referred to Autoimmune Polyendocrine 
1 Syndrome Type II (APS II) when they occur in the same individual, and sometimes these two

2 diseases even coexist in the same family $(6,7)$. Both T1DM and AITD develop through a

3 complex interaction of genetic and environmental factors and result in autoimmune

4 destruction of the specific organs involving both humoral and cellular immune responses (1,

$52,4,8,9)$. Many studies have showed prevalence rate of thyroid autoantibodies range from

$6 \quad 3.7-35 \%$ in T1DM patients, some of which suggested the associations between thyroid

7 autoantibodies and islet autoantibodies(10-14). However, little work has been done about the anti-islet autoimmune status in patients with AITD. As summarized in Additional File 1, the

9 prevalence rates of glutamic acid decarboxylase autoantibodies (GADA), islet cell 10 autoantibodies (ICA), insulinoma 2-associated autoantibodies (IA-2A) and insulin autoantibodies (IAA) in patients with AITD were either slightly or significantly higher than those in healthy controls, indicating there may be distinct immune status in different cohort. Besides these classic islet autoantibodies (GADA, IA2-A, ICA and IAA), ZnT8A is the recently identified new marker of autoimmunity in diabetes (15). Furthermore, the presence of ZnT8A predisposes non-obese adult-onset diabetes patients to $\operatorname{AITD}(16)$. However, there has been no clinical study based on large population focus on ZnT8A in AITD patients without T1DM.

In our study, we measured three islet autoantibodies, namely ZnT8A, GADA and IA-2A in AITD patients without T1DM and also studied the relationship between islet autoantibodies and thyroid autoantibodies. In addition, the prevalence rates among AITD, T1DM with AITD, non-autoimmune thyroid disease (nAITD) patients and healthy controls were compared to explore the anti-islet autoimmune condition. The data gained in this analysis are supposed to provide a rationale for screening programs for active case-finding strategies in specialized centers. 


\section{$1 \quad$ Research Design and Methods}

\section{Subjects}

A total of 740 Chinese patients with AITD, but without T1DM (600 female and 140 male; aged $40.4 \pm 14.0$ years; body mass index [BMI] $22.44 \pm 3.23 \mathrm{~kg} / \mathrm{m}^{2}$ ) were recruited in our study. The AITD patients consisted of 377 patients with Graves' disease and 363 patients with Hashimoto's thyroiditis. Autoimmune thyroid diseases were diagnosed clinically by endocrinologists and confirmed by abnormal levels of thyroid hormones and autoantibodies to thyrotropin receptor, thyroid peroxidase, and/or thyroglobulin. 108 patients with T1DM and AITD (67 female and 41 male; aged $32.7 \pm 17.5$ years; BMI $20.76 \pm 3.42 \mathrm{~kg} / \mathrm{m}^{2}$ ) were recruited in our study. Individuals with T1DM were diagnosed according to the diagnosis criteria of World Health Organization and American Diabetes Association. 172 patients (141 female and 31 male; aged 50.3 \pm 13.7 years; BMI $23.50 \pm 3.40 \mathrm{~kg} / \mathrm{m}^{2}$ ) with non-autoimmune thyroid disease (nAITD) such as subacute thyroiditis or thyroid nodules and 115 healthy controls ( 87 female and 28 male; aged $44.7 \pm 12.8$ years; BMI $21.42 \pm 2.56 \mathrm{~kg} / \mathrm{m}^{2}$ ) were also included as control groups. Sera of patients with AITD or nAITD and healthy controls were obtained in the endocrinology department of the First Affiliated Hospital of Nanjing Medical University from October 2010 to September 2013, and sera of patients with T1DM and AITD were obtained at 26 centers in China from June 2010 to Oct 2012.The clinical characteristics of all subjects are summarized in Additional File 2.

Our study was approved by the appropriate ethical committees, and informed consent was obtained from all participants.

\section{Islet autoantibody assay}

Serum islet autoantibodies were measured by radioligand binding assay as previously described (16), using ${ }^{35}$ S-labeled glutamic acid decarboxylase-65 (GAD65), 
1 protein-tyrosine-phosphatase-2 (IA-2) and zinc transporter 8 (ZnT8). Antibody levels were

2 expressed as an immunoprecipitation index, which is defined as (sample - negative control)/

3 (positive control - negative control). The cut-off for positivity for GADA, IA-2A and ZnT8A

4 was defined as a value above $0.048,0.018$, and 0.015 respectively, based on the 99th

5 percentile of 102, 315 and 218 healthy control subjects (non-diabetic individuals without

6 known autoimmune disease and no family history of diabetes). To compare the distribution

7 and activity of three islet autoantibodies, islet autoantibody relative value was defined as islet

8 autoantibody index/cut-off value.

9 Our laboratory has been validated in Islet Autoantibody Standardization Program 2020

10 with $60 \%$ study sensitivity and $100.0 \%$ study specificity for GADA, $70 \%$ study sensitivity and $100 \%$ study specificity for IA2A and $62 \%$ study sensitivity and $100.0 \%$ study specificity for ZnT8A. and TRAb, 0-1.5 IU/L. 
used to compare groups, and Kruskal-Wallis test was used for multigroup measurement data with unequal variances. The difference between classified variables was tested using $\chi^{2}$ or Fisher's exact test if the expected number of subjects in any cell was less than five. Multivariate linear regression model was used to analyze the correlation of measurement data. Statistical significance was defined as $\mathrm{P}<0.05$.

\section{Results}

1. Prevalence of thyroid autoantibodies and islet autoantibodies in AITD patients

Among 644 AITD patients with three thyroid autoantibodies detected at the time of blood samples collection, the prevalence of TPOAb, TGAb and TRAb was 77.48\%, 61.96\% and $49.22 \%$ respectively (Fig.1A).

All of 740 AITD patients' sera were measured three islet autoantibodies. A total of 177 (23.92\%) AITD patients were positive for any of the three islet autoantibodies (Fig.1B).

\section{Comparison of prevalence and level of islet autoantibodies in different groups}

The prevalence of islet autoantibodies in AITD patients was higher than that in healthy controls (ZnT8A: $15.00 \%$ vs 1.74\%, P<0.05; IA-2A: 4.19\% vs 0\%, P<0.05; GADA: 7.97\% vs $0.87 \%, \mathrm{P}<0.05$; $\geq 1$ islet $\mathrm{Ab}: 18.92 \%$ vs $2.61 \%, \mathrm{P}<0.05)$, although lower than that in patients with T1DM and AITD (ZnT8A: 15.00\% vs 47.22\%; IA-2A: 4.19\% vs 44.44\%; GADA: $7.97 \%$ vs 74.07\%; $\geqslant 1$ islet Ab: $18.92 \%$ vs $88.89 \%$; $\geqslant 2$ islet $\mathrm{Ab}: 2.16 \%$ vs $50.00 \%$, all $\mathrm{P}<0.05)($ Fig.2A,B,C and Additional File 3). Furthermore, in the groups of nAITD and healthy controls, there were no subject with more than one islet autoantibody positive.

Islet autoantibody relative value (i.e. ZnT8A, GADA and IA-2A relative value) was established to compare the level of islet autoantibodies. We confirmed significantly higher means of three islet autoantibody relative values in the T1DM patients with AITD compared with the AITD patients (all $\mathrm{p}<0.01$ ). We also observed a significant increase of mean IA-2A 
and GADA relative value in the AITD patients compared with healthy control subjects $(\mathrm{p}<$ 0.01), and a significantly higher mean GADA relative value in the AITD patients compared with the nAITD patients $(\mathrm{p}<0.01)$. We even noticed that ZnT8A, IA-2A and GADA relative value in T1DM with AITD group were widely distributed and there were more markedly higher values than in other conditions (the highest were up to 80,80 and 40, respectively), while the distributions in AITD, nAITD and healthy control group were relatively centralized (most of them were less than 5), except for some slightly high GADA relative values in AITD group and several high ZnT8A and IA2A relative values in AITD group and nAITD group (Fig.2D,E,F).

3. Comparison of prevalence and level of islet autoantibodies and thyroid autoantibodies between Graves disease and Hashimoto's thyroiditis subjects

When AITD patients were divided into 2 subgroups, namely Graves' disease (GD) and Hashimoto's thyroiditis (HT), we observed significantly higher frequencies of either TPOAb or TGAb in the HT patients compared with the GD patients (TPOAb: $81.76 \%$ vs $72.89 \%$; TGAb: $81.79 \%$ vs $44.67 \%$, both $\mathrm{P}<0.01$ ), while the prevalence of TRAb was significantly higher in the GD patients compared with the HT patients $(82.70 \%$ vs $13.84 \%, \mathrm{P}<0.01)$ (Additional File 4B). In addition, the distributions of TPOAb, TGAb and TRAb titers in the two subgroups had the similar tendency (Additional File 5 A,B,C). Neverthless, it is remarkable to note that the prevalence of any islet autoantibody, at least one islet autoantibody and at least two islet autoantibodies did not differ significantly between subgroups (GD vs. HT : ZnT8A $13.79 \%$ vs $16.25 \%$; IA-2A $4.51 \%$ vs 3.86\%; GADA 8.49\% vs $7.44 \%$; $\geq 1$ islet $\mathrm{Ab}: 23.34 \%$ vs $24.52 \%$; $\geq 2$ islet $\mathrm{Ab}: 3.18 \%$ vs $2.48 \%$, all $\mathrm{P}>0.05$ ) (Additional File 4A). Apart from this, three islet autoantibody relative values were also compared and no statistically significant differences were found between subgroups (all P> 0.05, Additional File 5 D,E,F). 
1 4. Characteristics of islet autoantibody - positive and - negative AITD patients

When AITD patients positive for TPOAb (>34 IU/ml) were divided into 2 subgroups according to the titer of TPOAb, namely a high-titer subgroup ( $\geq 600 \mathrm{IU} / \mathrm{ml})$ and a low-titer subgroup $(<600 \mathrm{IU} / \mathrm{ml})$, so that there were 150 and 377 subjects, respectively. We observed increased prevalence of IA-2A, GADA and at least one islet autoantibody in the AITD patients with high-titer TPOAb (GADA: $12.67 \%$ vs 5.84\%; IA-2A: $7.33 \%$ vs $2.39 \%$, both $p<$ 0.01 ; $\geq 1$ islet $\mathrm{Ab}: 31.33 \%$ vs $22.55 \%, \mathrm{P}<0.05$ ). In addition, there was a trend for higher prevalence of ZnT8A in the AITD patients with high-titer TPOAb compared with those with low-titer TPOAb, but this difference did not reach statistical significance (19.33\% vs $15.38 \%$, $\mathrm{P}>0.05$ ) (Fig.3A). The level of three islet autoantibodies was further analyzed between subgroups, but we only observed a higher mean IA-2A relative value in the high-titer TPOAb patients with the borderline significance ( $\mathrm{P}=0.046$, Additional File 6). When it comes to the comparison of the prevalence for high-titer TPOAb between islet autoantibody - positive and - negative AITD patients, a larger proportion of patients with high-titer TPOAb was found in the islet autoantibody - positive AITD patients except for ZnT8A-positive patients (Table 1).

However, the prevalence for any islet autoantibody as well as at least one islet autoantibody differ little with the titer of TPOAb or TGAb increased (Fig.3B,C), and we did not find statistically significant differences in either TPOAb or TGAb positive rate between the AITD patients with islet autoantibody - positive and - negative, either. Besides, there were no statistically significant differences in sexual proportion, subtypes of disease, age, duration, prevalence of type 2 diabetes mellitus (T2DM), antithyroidal treatment, and level of either TSH or FT4 between islet autoantibody - positive and - negative AITD patients(Table 1), except for a borderline statistical significance $(\mathrm{P}=0.048)$ in BMI between ZnT8A positive and - negative AITD patients, and statistically increases in BMI and TRAb positive rate between IA-2A - positive and - negative AITD patients (Table 1).These findings suggest 
an increase level of islet autoimmunity independent of subtypes of disease, gender, age, duration, concurrent type 2 diabetes mellitus, anti-thyroidal treatment, TPOAb or TGAb positivity and thyroid function.

$$
\text { (please put table1 here) }
$$

In the analysis of multivariable linear regression, we found that $\mathrm{ZnT}$ 8A relative value was positively correlated with GADA relative value $(\beta=0.352, \mathrm{P}<0.01)$ and TPOAb titer $(\beta=0.002$, $\mathrm{P}<0.01$ ), and GADA relative value was also positively correlated with ZnT8A relative value $(\beta=0.183, \mathrm{P}<0.01)($ Additional File 7). Apart from this, IA-2A relative value showed no association with any of above.

\section{Discussion}

Here we are the first to show that the prevalence of ZnT8A was as high as $15.00 \%$ in the AITD patients, and as expected, was significantly higher than that in the healthy controls. It was also a novel finding that the prevalence rate of ZnT8A was much higher than that of GADA (7.97\%) in the AITD population, as the latter in the previous studies was the highest (17-21). Previous evidences have already shown that ZnT8A is frequent in a lot of endocrine or autoimmune disorders. As in the report from Wenzlau et al.(15), ZnT8A occurred in 60-80\% of new-onset T1DM, in less than $2 \%$ of controls, in less than 3\% of T2DM and in up to $30 \%$ of non-diabetic patients with other autoimmune disorders with a T1DM association. In accordance with these findings, our study observed that the prevalence of ZnT8A in AITD was significantly lower than that in T1DM, but was still slightly higher or significantly higher than that in nAITD or healthy subjects. Rydzewska et al. (22) held the opinion that the existence of ZnT8A in AITD patients may play an important role in the immune bystander responses towards ZnT8 protein expressed on thyroid. To further investigate that, thyroidectomy species have been collected from patients with thyroid nodular goiter and GD 
1 and dealt with Immunohistochemical staining. The strong ZnT8 staining could been observed

2 in almost all of the thyroid follicular cells and some of the cytoplasm and the perinuclear area

3 of the hyperplastic $\mathrm{C}$ cells. In accordance with the observations mentioned before, ZnT8 was

4 identified to be a major autoantigen in human type 1 diabetes and localized into insulin

5 secretory granules $(15,23)$, and it also expressed in other secretory cell types of murine like

6 pancreatic $\alpha$ islet cells, thyroid cubical cells and adrenal gland cortex cells (24), so our data

7 further confirm the widespread role of ZnT8 in the endocrine system $(15,24,25)$. In addition, we observed significant differences in the level of ZnT8A between T1DM with AITD and

9 AITD, while there were no statistical differences between AITD and nAITD or healthy

10 controls. These results can be explained by the non-specificity of ZnT8A appearing in the 11 AITD patients without T1DM. Interesting, despite the finding that no statistical differences were observed in the prevalence rate and level of $\mathrm{ZnT} 8 \mathrm{~A}$ regarding comparison on TPOAb in our study, we still found an association among the level of ZnT8A, GADA and TPOAb. Given that Rogowicz-Frontczaket al.(16) revealed an association among positive ZnT8A, association between two thyroid autoantibodies (TPOAb and TGAb) and ZnT8A or GADA positivity in a large population of newly diagnosed T1DM children, taken together we conclude that there is a potential link between thyroid autoimmunity and islet autoimmunity in autoimmune thyroid disease. Longitudinal studies are necessary to determine the predict value of both GADA and ZnT8A positive in patients with AITD for developing T1DM.

Measurements of GADA and IA-2A are recommended for initial confirmation of the suspected diagnosis of T1DM or for the prediction of T1DM in research settings(26).Our prevalence of either GADA or IA-2A was similar to findings in the previous studies $(18,19$, 27-29). While there was a significantly lower frequency and level of either GADA or IA-2A in the AITD patients compared with that in the T1DM patients, the results were still 
1 significant higher than in the healthy subjects, thus partly confirmed the findings on GADA

2 of Kawasaki et al.(19). Take into consideration the early study from Kawasaki et al.(30)which

3 demonstrated that the level of GADA in T1DM with AITD were found to be significantly

4 higher than in patients without AITD, and the recent Chinese study revealing the high level of

5 GADA to be a strong predictor of the development of thyroid autoimmunity in patients with

6 autoimmune diabetes (31), as well as the finding of Lethagen et al.(32) that GADA positivity

7 could be a marker of subclinical insulitis in non-diabetic patients with autoimmune thyroiditis, and the strong connection which Brorsson et al.(9) figured out that GADA is related to both increasing age and human leukocyte antigen (HLA) DQ2/DR3, we conclude that the presence of GADA may be a marker of concurrent or successive thyroid autoimmunity and islet autoimmunity. Piliaet al.(18)observed that IA-2A was significantly prevalent in Sardinian children with autoimmune thyroiditis, which is consistent with our results to some degree, however, their prevalence of GADA showed no significant differences compared with healthy adolescents and the patients were only with autoimmune thyroiditis, which may explain the discordance with our results. Remarkably, despite our findings that the positive rate of either GADA or IA-2A did not vary much with TPOAb titer increasing, we observed a significant higher frequency of GADA and IA-2A in the AITD patients with high-titer TPOAb, and also a higher prevalence of high-titer TPOAb in the GADA- or IA-2A- positive patients, therefore we infer that AITD patients, not only those with Hashimoto's thyroiditis, with high-titer TPOAb tend to have more islet autoimmunity. Besides, to our knowledge, it is the first time that a statistically higher TRAb positive rate was found in IA-2A-positive AITD patients compared with IA-2A-negative AITD patients, so further studies are demanded to elucidate their relationship.

Our large cohort made it possible to compare the prevalence of three islet autoantibodies 
between populations with AITD without T1DM and T1DM with AITD, nAITD or healthy subjects, thereby allowing us to determine the islet autoimmunity in AITD. Islet autoantibodies were measured by a sensitive radioligand binding assay, which was confirmed by our laboratory performance characteristics from Islet Autoantibody Standardization Program certification of 2020 workshop participation. Moreover, although other studies have shown that patients with AITD are at increased risk of developing T1DM $(18,33)$, which were mainly based on the follow-up of one autoantibody. It is believed that the presence of any one single autoantibody appears not to be of predictive value for the disease (34-36). Therefore, we infer that the AITD patients with two or more islet autoantibodies positive, especially those also with high-titer TPOAb, are at high risk of progressing to T1DM. However, limited to that our study was cross-sectional and case-control, there was no long-term follow up and the other two islet autoantibodies were not measured, thus the functional changes of islet $\beta$ cells and anti-islet autoimmune status remains to be clarified in future longitudinal studies. Besides, the discordance of sexual proportion and age between patients with AITD and T1DM as well as multiple statistical comparisons may decrease the statistical power.

\section{Conclusions}

In conclusion, an increased prevalence of ZnT8A as well as a relatively high prevalence of islet autoimmunity was found in patients with autoimmune thyroid disease. It indicates there is a potential link between thyroid autoimmunity and islet autoimmunity. The presence of GADA may be a marker of concurrent or successive thyroid autoimmunity and islet autoimmunity, and patients with high-titer TPOAb tend to have more islet autoimmunity in autoimmune thyroid disease. We suggest, therefore, patients with autoimmune thyroid disease who also have a high-titer TPOAb, may need screening for blood glucose and islet 
1 autoantibodies, and those found with two or more islet autoantibodies positive may need

2 long-term follow-up for islet dysfunction.

Autoimmune Thyroid Disease

6

nAITD

non-Autoimmune Thyroid Disease

7

GD

Graves' Disease

8

HT

Hashimoto's Thyroiditis

9

T1DM

Type 1 Diabetes Mellitus

10

T2DM

Type 2 Diabetes Mellitus

ZnT8A

Zinc Transporter 8 Autoantibodies

Glutamic Acid Decarboxylase Autoantibody

Protein Tyrosine Phosphatase-2 Autoantibody

Insulin Autoantibody

Islet Cell Autoantibody

Thyroid Peroxidase Antibody

Thyrotropin Receptor Antibody

Thyroglobulin Antibody

Autoimmune Polyendocrine Syndromes

Body Mass Index

Free Tetraiodothyronine

Free Triiodothyronine

Thyroid-stimulating Hormone

Human Leukocyte Antigen 


\section{Declarations}

\section{Ethics approval and consent to participate}

The experimental protocol was approved by the Ethics Committee of the First Affiliated

5 Hospital of Nanjing Medical University and conformed to the provisions of the Declaration

6 of Helsinki (Ethical approval No. 2010-SR-021).

\section{Consent for publication}

Not applicable.

\section{Availability of data and materials}

corresponding author on reasonable request. and Z.X.Q. contributed to design of the study and reviewed and edited the manuscript. Y.L.P. help to take control of the autoantibodies assay. All authors reviewed and take full responsibility for the contents of the manuscript. Y.T is the guarantor of this work and, as such, had full access to all the data in the study and takes responsibility for the integrity of the 
for their tutoring and guidance.

\section{References}

2. Pearce EN, Farwell AP, Braverman LE. Thyroiditis. The New England journal of medicine. 2003;348(26):2646-55.

3. Golden B, Levin L, Ban Y, Concepcion E, Greenberg DA, Tomer Y. Genetic analysis of families with autoimmune diabetes and thyroiditis: evidence for common and unique genes. J Clin Endocrinol Metab. 2005;90(8):4904-11.

4. Barker JM, Yu J, Yu L, Wang J, Miao D, Bao F, et al. Autoantibody "subspecificity" in type 1 diabetes: risk for organ-specific autoimmunity clusters in distinct groups. Diabetes Care. 2005;28(4):850-5.

5. De Block CE, De Leeuw IH, Vertommen JJ, Rooman RP, Du Caju MV, Van Campenhout CM, et al. Beta-cell, thyroid, gastric, adrenal and coeliac autoimmunity and HLA-DQ types in type 1 diabetes. Clin Exp Immunol. 2001;126(2):236-41.

6. Eisenbarth GS, Gottlieb PA. Autoimmune polyendocrine syndromes. The New England journal of medicine. 2004;350(20):2068-79.

7. Jenkins RC, Weetman AP. Disease associations with autoimmune thyroid disease. Thyroid. 2002;12(11):977-88.

8. Eisenbarth GS. Type I diabetes mellitus. A chronic autoimmune disease. The New England journal of medicine. 1986;314(21):1360-8.

9. Brorsson CA, Pociot F. Shared Genetic Basis for Type 1 Diabetes, Islet Autoantibodies, and Autoantibodies Associated With Other Immune-Mediated Diseases in Families With Type 1 Diabetes. Diabetes Care. 2015;38 Suppl 2:S8-13.

10. Holl RW, Bohm B, Loos U, Grabert M, Heinze E, Homoki J. Thyroid autoimmunity in children and adolescents with type 1 diabetes mellitus. Effect of age, gender and HLA type. Horm Res. 1999;52(3):113-8.

11. Jonsdottir B, Andersson C, Carlsson A, Delli A, Forsander G, Ludvigsson J, et al. Thyroid autoimmunity in relation to islet autoantibodies and HLA-DQ genotype in newly diagnosed type 1 diabetes in children and adolescents. Diabetologia. 2013;56(8):1735-42.

12. Hanukoglu A, Mizrachi A, Dalal I, Admoni O, Rakover Y, Bistritzer Z, et al. Extrapancreatic autoimmune manifestations in type 1 diabetes patients and their first-degree relatives: a multicenter study. Diabetes Care. 2003;26(4):1235-40.

13. Jaeger C, Hatziagelaki E, Petzoldt R, Bretzel RG. Comparative analysis of organ-specific autoantibodies and celiac disease--associated antibodies in type 1 diabetic patients, their first-degree relatives, and healthy control subjects. Diabetes Care. 2001;24(1):27-32.

14. Bonifacio E, Mayr A, Knopff A, Ziegler AG. Endocrine autoimmunity in families with type 1 diabetes: frequent appearance of thyroid autoimmunity during late childhood and adolescence. Diabetologia. 2009;52(2):185-92.

15. Wenzlau JM, Juhl K, Yu L, Moua O, Sarkar SA, Gottlieb P, et al. The cation efflux transporter ZnT8 (Slc30A8) is a major autoantigen in human type 1 diabetes. Proc Natl Acad Sci USA. 2007;104(43):17040-5.

16. Rogowicz-Frontczak A, Zozuliłska-Ziołkiewicz D, Litwinowicz M, Niedźwiecki P, Wyka K, Wierusz-Wysocka B. Are zinc transporter type 8 antibodies a marker of autoimmune thyroiditis in non-obese adults with new-onset diabetes? European journal of endocrinology. 2014;170(4):651-8.

17. Gu Y, Zhang M, Chen H, Wang Z, Xing C, Yang H, et al. Discordant association of islet autoantibodies with high-risk HLA genes in Chinese type 1 diabetes. Diabetes Metab Res Rev. 2011;27(8):899-905.

18. Pilia S, Casini MR, Cambuli VM, Ibba A, Civolani P, Zavattari P, et al. Prevalence of Type 1 diabetes autoantibodies (GAD and IA2) in Sardinian children and adolescents with autoimmune thyroiditis. Diabet Med. 2011;28(8):896-9.

19. Kawasaki E, Abiru N, Yano M, Uotani S, Matsumoto K, Matsuo H, et al. Autoantibodies to glutamic acid decarboxylase in patients with autoimmune thyroid disease: relation to competitive insulin autoantibodies. J Autoimmun. 1995;8(5):633-43. 
20. Pietropaolo M, Peakman M, Pietropaolo SL, Zanone MM, Foley TP, Becker DJ, et al. Combined analysis of GAD65 and ICA512(IA-2) autoantibodies in organ and non-organ-specific autoimmune diseases confers high specificity for insulin-dependent diabetes mellitus. J Autoimmun. 1998;11(1).

21. Maugendre D, Vérité F, Guilhem I, Genetet B, Allannic H, Delamaire M. Anti-pancreatic autoimmunity and Graves' disease: study of a cohort of 600 Caucasian patients. European journal of endocrinology. 1997;137(5):503-10.

22. Rydzewska M, Michalak J, Bossowska A, Chen S, Black S, Powell M, et al. Analysis of diabetes-associated autoantibodies in children and adolescents with autoimmune thyroid diseases. J Pediatr Endocrinol Metab. 2019;32(4):355-61.

23. Chimienti F, Devergnas S, Favier A, Seve M. Identification and cloning of a beta-cell-specific zinc transporter, ZnT-8, localized into insulin secretory granules. Diabetes. 2004;53(9):2330-7.

24. Murgia C, Devirgiliis C, Mancini E, Donadel G, Zalewski P, Perozzi G. Diabetes-linked zinc transporter ZnT8 is a homodimeric protein expressed by distinct rodent endocrine cell types in the pancreas and other glands. Nutr Metab Cardiovasc Dis. 2009;19(6):431-9.

25. Jonsdottir B, Jönsson I, Lantz M. Prevalence of diabetes and presence of autoantibodies against zinc transporter 8 and glutamic decarboxylase at diagnosis and at follow up of Graves' disease. Endocrine. 2019;64(1):48-54.

26. Winter WE, Schatz DA. Autoimmune markers in diabetes. Clin Chem. 2011;57(2):168-75.

27. Moriguchi M, Noso S, Kawabata Y, Yamauchi T, Harada T, Komaki K, et al. Clinical and genetic characteristics of patients with autoimmune thyroid disease with anti-islet autoimmunity. Metab Clin Exp. 2011;60(6):761-6.

28. Primo ME, Niepomniszcze H, Poskus E, Sala MS, Guaita SS, Sica MP, et al. Frequency of pancreatic beta-cell autoimmunity markers in patients with autoimmune thyroid disease. Medicina (B Aires). 2008;68(1):37-42.

29. Jonsdottir B, Larsson C, Carlsson A, Forsander G, Ivarsson SA, Lernmark Å, et al. Thyroid and Islet Autoantibodies Predict Autoimmune Thyroid Disease at Type 1 Diabetes Diagnosis. J Clin Endocrinol Metab. 2017;102(4):1277-85.

30. Kawasaki E, Takino H, Yano M, Uotani S, Matsumoto K, Takao Y, et al. Autoantibodies to glutamic acid decarboxylase in patients with IDDM and autoimmune thyroid disease. Diabetes. 1994;43(1):80-6.

31. Jin P, Huang G, Lin J, Yang L, Xiang B, Zhou W, et al. High titre of antiglutamic acid decarboxylase autoantibody is a strong predictor of the development of thyroid autoimmunity in patients with type 1 diabetes and latent autoimmune diabetes in adults. Clin Endocrinol (Oxf). 2011;74(5):587-92.

32. Lethagen AL, Ericsson UB, Hallengren B, Groop L, Tuomi T. Glutamic acid decarboxylase antibody positivity is associated with an impaired insulin response to glucose and arginine in nondiabetic patients with autoimmune thyroiditis. J Clin Endocrinol Metab. 2002;87(3):1177-83.

33. Taniyama M, Kasuga A, Nagayama C, Ito K. Occurrence of type 1 diabetes in graves' disease patients who are positive for antiglutamic Acid decarboxylase antibodies: an 8-year followup study. J Thyroid Res. 2010;2011:306487.

34. Gorus FK, Goubert P, Semakula C, Vandewalle CL, De Schepper J, Scheen A, et al. IA-2-autoantibodies complement GAD65-autoantibodies in new-onset IDDM patients and help predict impending diabetes in their siblings. The Belgian Diabetes Registry. Diabetologia. 1997;40(1):95-9.

35. Bingley PJ, Bonifacio E, Williams AJ, Genovese S, Bottazzo GF, Gale EA. Prediction of IDDM in the general population: strategies based on combinations of autoantibody markers. Diabetes. 1997;46(11):1701-10.

36. Schlosser M, Strebelow M, Wassmuth R, Arnold M-L, Breunig I, Rjasanowski I, et al. The Karlsburg type 1 diabetes risk study of a normal schoolchild population: association of beta-cell autoantibodies and human leukocyte antigen-DQB1 alleles in antibody-positive individuals. J Clin Endocrinol Metab. 2002;87(5):2254-61. 
Figure 1. Frequency of islet autoantibodies and thyroid autoantibodies in autoimmune thyroid diseases subjects.

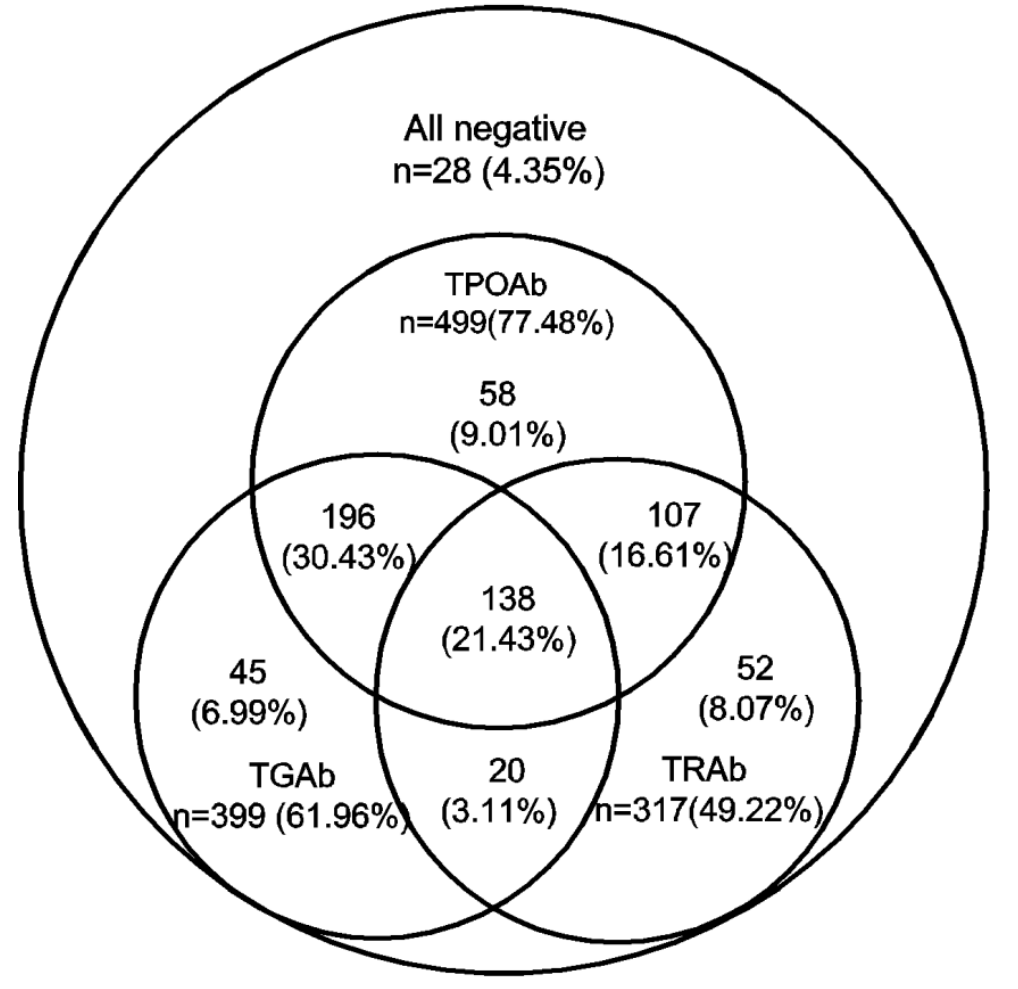

A

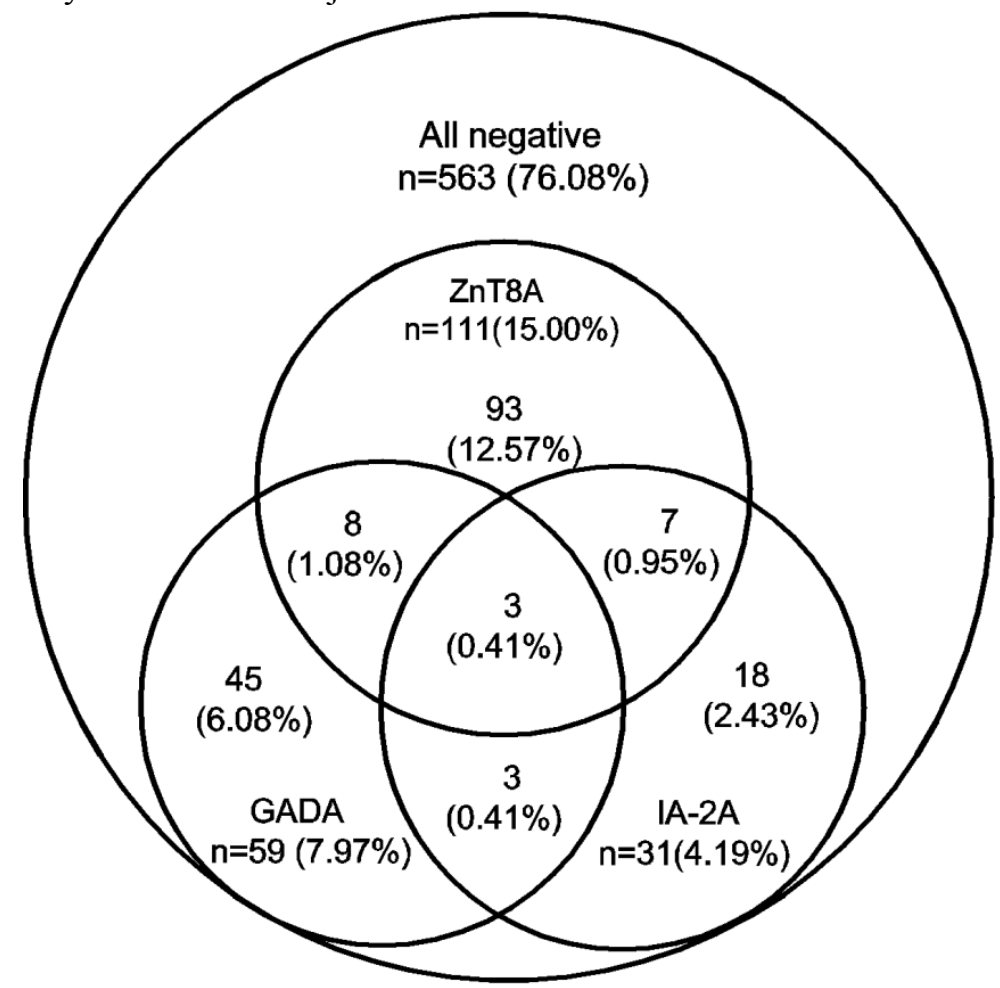

B

Figure 1A. Frequency of thyroid autoantibodies is shown in $\mathbf{6 4 4}$ patients with autoimmune thyroid diseases. Of these, $\mathbf{6 1 6}(\mathbf{9 5 . 6 5 \%})$ were positive for at least one thyroid autoantibody.

Figure 1B. Frequency of islet autoantibodies is shown in $\mathbf{7 4 0}$ patients with autoimmune thyroid diseases. Of these, $\mathbf{1 7 7}(\mathbf{2 3 . 9 2 \% )}$ were positive for at least one islet autoantibody 
Figure2. Frequency of islet autoantibodies in T1DM with AITD, AITD, nAITD and HC subjects.
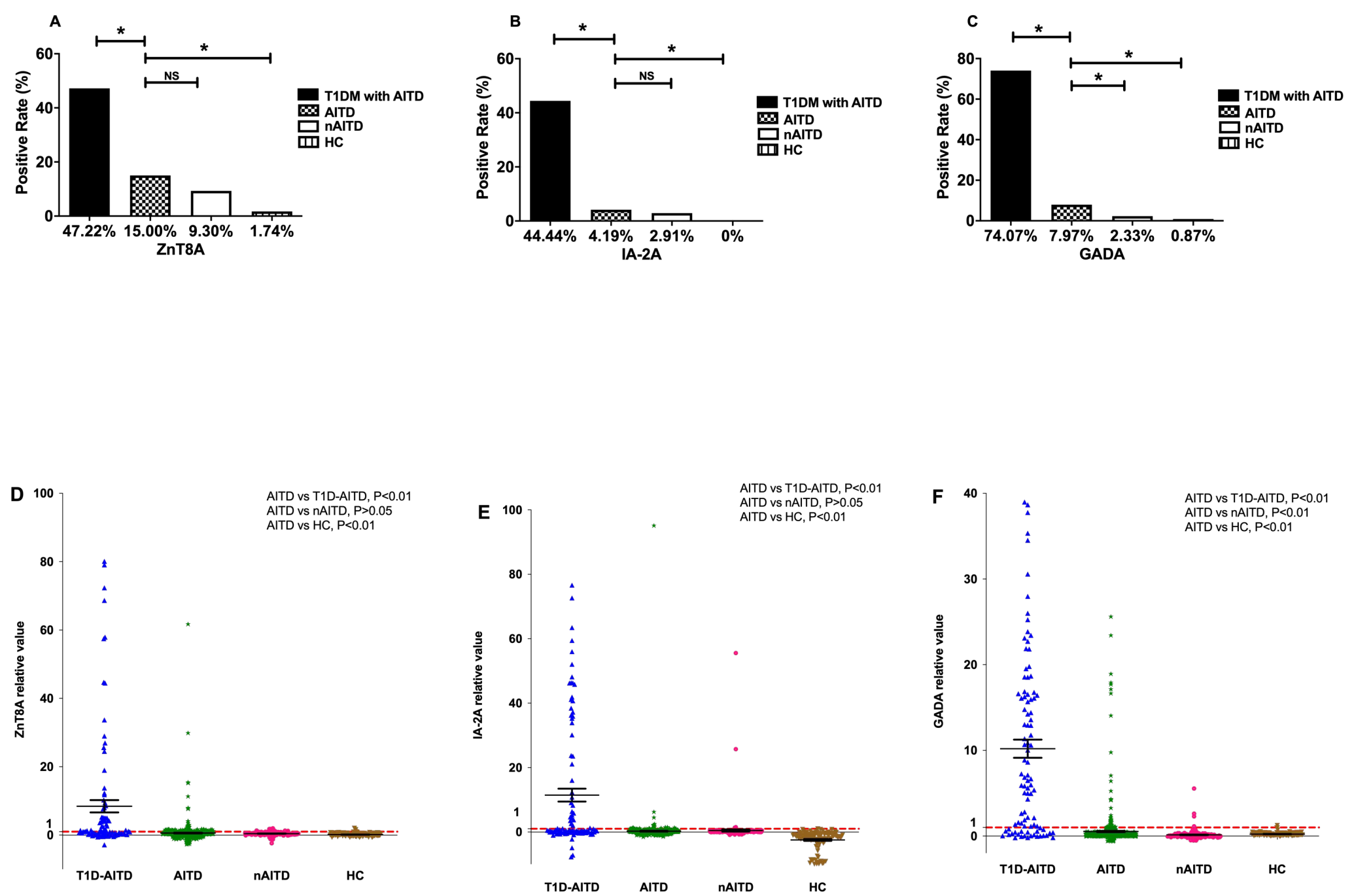
Figure3. Frequency of islet autoantibodies in AITD subjects with high titer TPOAb and low titer TPOAb.
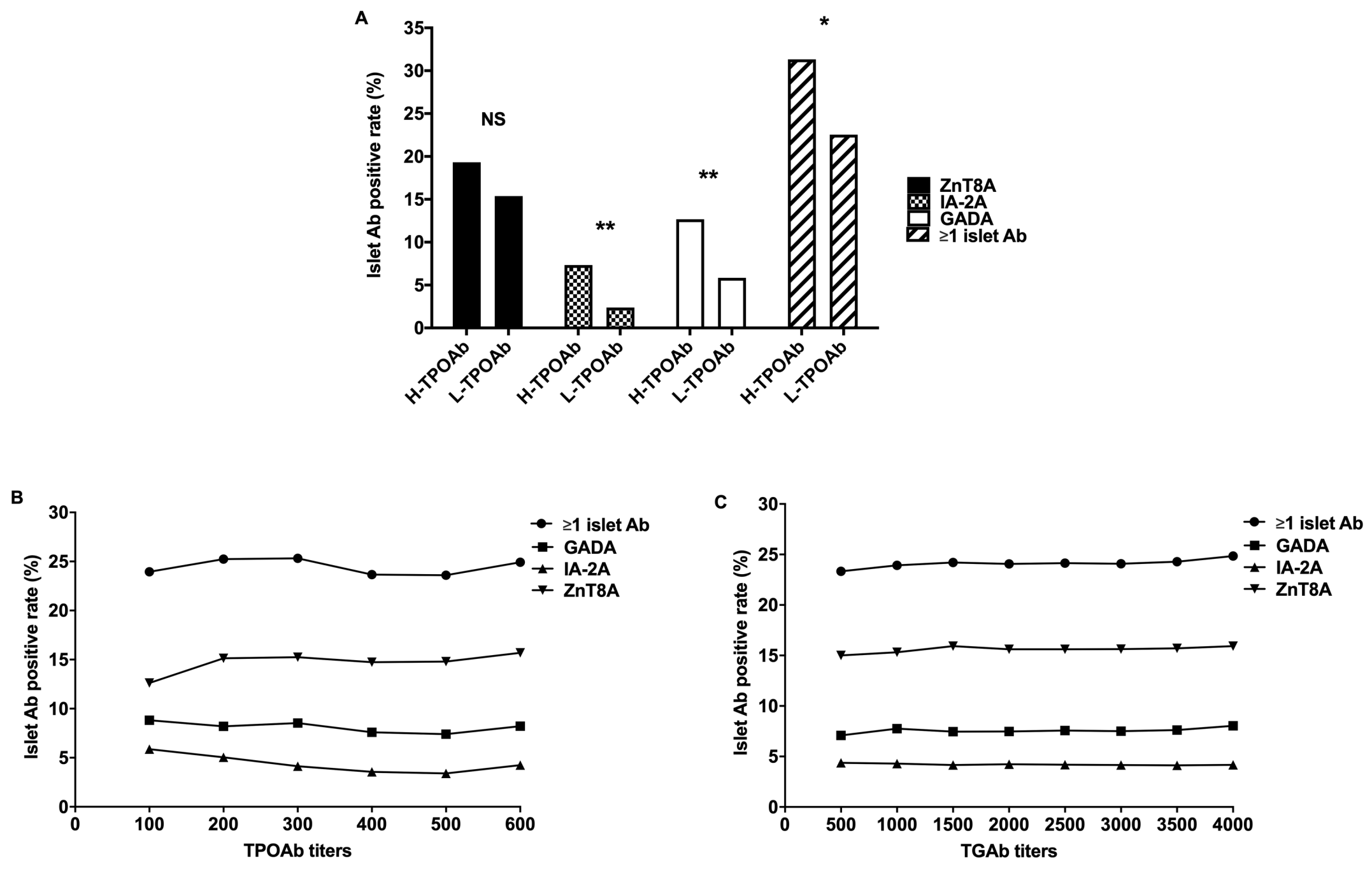
1 Table1. Clinical characteristics of eight subgroups of autoimmune thyroid diseases subjects.

\begin{tabular}{|c|c|c|c|c|c|c|c|c|c|c|c|c|}
\hline & \multicolumn{8}{|c|}{ Subgroup } & \multicolumn{4}{|c|}{ P Value } \\
\hline & $\begin{array}{c}\mathrm{ZnT8A}+ \\
(\mathrm{n}=111)\end{array}$ & $\begin{array}{l}\text { ZnT8A- } \\
(n=629)\end{array}$ & $\begin{array}{c}\text { GADA+ } \\
(n=59)\end{array}$ & $\begin{array}{l}\text { GADA- } \\
(\mathrm{n}=681)\end{array}$ & $\begin{array}{c}\text { IA-2A+ } \\
(\mathrm{n}=\mathbf{3 1})\end{array}$ & $\begin{array}{l}\text { IA-2A- } \\
(n=709)\end{array}$ & $\begin{array}{c}\text { Islet Ab+ } \\
(\mathbf{n}=177)\end{array}$ & $\begin{array}{c}\begin{array}{c}\text { Islet Ab- } \\
(\mathrm{n}=563)\end{array} \\
\end{array}$ & $\mathbf{P}_{\mathbf{a}}$ & $\mathbf{P}_{\mathbf{b}}$ & $\mathbf{P}_{\mathbf{c}}$ & $\mathbf{P}_{\mathbf{d}}$ \\
\hline $\begin{array}{c}\operatorname{Sex}(\text { female/male }) \\
\text { (n) }\end{array}$ & $95 / 16$ & $505 / 124$ & $49 / 10$ & $551 / 130$ & $27 / 4$ & $573 / 136$ & $147 / 30$ & $453 / 110$ & $>0.05$ & $>0.05$ & $>0.05$ & $>0.05$ \\
\hline $\begin{array}{l}\text { Disease } \\
\text { (GD/HT) }\end{array}$ & $52 / 59$ & $325 / 304$ & $32 / 27$ & $345 / 336$ & $17 / 14$ & $360 / 349$ & $88 / 89$ & $289 / 274$ & $>0.05$ & $>0.05$ & $>0.05$ & $>0.05$ \\
\hline $\begin{array}{c}\text { Age } \\
\text { (years) }\end{array}$ & $\begin{array}{c}42 \\
(9-79)\end{array}$ & $\begin{array}{c}40.5 \\
(10-76)\end{array}$ & $\begin{array}{c}39 \\
(16-65)\end{array}$ & $\begin{array}{c}41 \\
(9-79)\end{array}$ & $\begin{array}{c}43 \\
(20-65)\end{array}$ & $\begin{array}{c}41 \\
(9-79)\end{array}$ & $\begin{array}{c}41.5 \\
(9-79)\end{array}$ & $\begin{array}{c}41 \\
(10-76)\end{array}$ & $>0.05^{\dagger}$ & $>0.05^{\dagger}$ & $>0.05^{\dagger}$ & $>0.05^{\dagger}$ \\
\hline $\begin{array}{c}\text { Duration } \\
\text { (years) }\end{array}$ & $2.78 \pm 4.85$ & $2.54 \pm 4.82$ & $2.36 \pm 4.23$ & $2.59 \pm 4.87$ & $2.87 \pm 4.10$ & $2.56 \pm 4.85$ & $2.66 \pm 4.37$ & $2.55 \pm 4.96$ & $>0.05^{\dagger}$ & $>0.05^{\dagger}$ & $>0.05^{\dagger}$ & $>0.05^{\dagger}$ \\
\hline$\underset{\left(\mathrm{Kg} / \mathbf{m}^{2}\right)}{\mathrm{BMI}}$ & $21.85 \pm 2.92$ & $22.54 \pm 3.27$ & $22.63 \pm 3.98$ & $22.42 \pm 3.15$ & $20.85 \pm 2.18$ & $22.51 \pm 3.25$ & $22.12 \pm 3.24$ & $22.54 \pm 3.22$ & $0.048^{\dagger}$ & $>0.05^{\dagger}$ & $<0.01^{\dagger}$ & $>0.05^{\dagger}$ \\
\hline $\begin{array}{l}\text { T2DM } \\
(\mathbf{n \% )}\end{array}$ & $\begin{array}{c}7 \\
(6.48 \%)\end{array}$ & $\begin{array}{c}26 \\
(4.19 \%)\end{array}$ & $\begin{array}{c}3 \\
(5.08 \%)\end{array}$ & $\begin{array}{c}30 \\
(4.48 \%)\end{array}$ & $\begin{array}{c}0 \\
(0.00 \%)\end{array}$ & $\begin{array}{c}33 \\
(4.73 \%)\end{array}$ & $\begin{array}{c}9 \\
(5.17 \%)\end{array}$ & $\begin{array}{c}24 \\
(4.33 \%)\end{array}$ & $>0.05$ & $>0.05$ & $>0.05$ & $>0.05$ \\
\hline $\begin{array}{c}\text { TPOAb+ } \\
\text { (n\%) }\end{array}$ & $\begin{array}{c}87 \\
(81.31 \%)\end{array}$ & $\begin{array}{c}441 \\
(76.56 \%)\end{array}$ & $\begin{array}{c}41 \\
(73.21 \%)\end{array}$ & $\begin{array}{c}487 \\
(77.67 \%)\end{array}$ & $\begin{array}{c}21 \\
(70.00 \%)\end{array}$ & $\begin{array}{c}507 \\
(77.64 \%)\end{array}$ & $\begin{array}{c}133 \\
(77.78 \%)\end{array}$ & $\begin{array}{c}395 \\
(77.15 \%)\end{array}$ & $>0.05$ & $>0.05$ & $>0.05$ & $>0.05$ \\
\hline $\begin{array}{c}\text { High-titer } \\
\text { TPOAb(n\%) }\end{array}$ & $\begin{array}{c}29 \\
(33.33 \%)\end{array}$ & $\begin{array}{c}121 \\
(27.50 \%)\end{array}$ & $\begin{array}{c}19 \\
(46.34 \%)\end{array}$ & $\begin{array}{c}131 \\
(26.95 \%)\end{array}$ & $\begin{array}{c}11 \\
(55.00 \%)\end{array}$ & $\begin{array}{c}139 \\
(27.42 \%)\end{array}$ & $\begin{array}{c}47 \\
(35.61 \%)\end{array}$ & $\begin{array}{c}103 \\
(26.08 \%)\end{array}$ & $>0.05$ & $<0.01$ & $<0.01$ & $<0.05$ \\
\hline
\end{tabular}




\begin{tabular}{|c|c|c|c|c|c|c|c|c|c|c|c|c|c|}
\hline & & \multicolumn{8}{|c|}{ Subgroup } & \multicolumn{4}{|c|}{ P Value } \\
\hline & & $\begin{array}{c}\mathrm{ZnT8A}+ \\
(\mathrm{n}=111)\end{array}$ & $\begin{array}{l}\text { ZnT8A- } \\
(n=629) \\
\end{array}$ & $\begin{array}{c}\text { GADA+ } \\
(n=59)\end{array}$ & $\begin{array}{l}\text { GADA- } \\
(n=681)\end{array}$ & $\begin{array}{c}\mathbf{I A - 2 A}+ \\
(\mathbf{n}=\mathbf{3 1})\end{array}$ & $\begin{array}{c}\text { IA-2A- } \\
(n=709)\end{array}$ & $\begin{array}{c}\text { Islet Ab+ } \\
(\mathbf{n}=\mathbf{1 7 7}) \\
\end{array}$ & $\begin{array}{c}\text { Islet Ab- } \\
(n=563)\end{array}$ & $\mathbf{P}_{\mathbf{a}}$ & $\mathbf{P}_{\mathbf{b}}$ & $\mathbf{P}_{\mathbf{c}}$ & $\mathbf{P}_{\mathbf{d}}$ \\
\hline & $\begin{array}{c}\text { TGAb+ } \\
(\mathbf{n} \%)\end{array}$ & $\begin{array}{c}73 \\
(68.22 \%)\end{array}$ & $\begin{array}{c}352 \\
(62.19 \%)\end{array}$ & $\begin{array}{c}34 \\
(62.96 \%)\end{array}$ & $\begin{array}{c}391 \\
(63.17 \%)\end{array}$ & $\begin{array}{c}15 \\
(51.72 \%)\end{array}$ & $\begin{array}{c}410 \\
(63.66 \%)\end{array}$ & $\begin{array}{c}109 \\
(64.88 \%)\end{array}$ & $\begin{array}{c}316 \\
(62.57 \%)\end{array}$ & $>0.05$ & $>0.05$ & $>0.05$ & $>0.05$ \\
\hline & $\begin{array}{c}\text { TRAb+ } \\
(\mathbf{n} \%)\end{array}$ & $\begin{array}{c}48 \\
(46.15 \%)\end{array}$ & $\begin{array}{c}278 \\
(50.09 \%)\end{array}$ & $\begin{array}{c}29 \\
(53.70 \%)\end{array}$ & $\begin{array}{c}297 \\
(49.09 \%)\end{array}$ & $\begin{array}{c}21 \\
(70.00 \%)\end{array}$ & $\begin{array}{c}305 \\
(48.49 \%)\end{array}$ & $\begin{array}{c}84 \\
(50.60 \%)\end{array}$ & $\begin{array}{c}242 \\
(49.09 \%)\end{array}$ & $>0.05$ & $>0.05$ & $<0.05$ & $>0.05$ \\
\hline & $\begin{array}{l}\text { Drug } \\
(n \%)\end{array}$ & $\begin{array}{c}76 \\
(68.47 \%)\end{array}$ & $\begin{array}{c}411 \\
(65.34 \%)\end{array}$ & $\begin{array}{c}32 \\
(54.24 \%)\end{array}$ & $\begin{array}{c}455 \\
(66.81 \%)\end{array}$ & $\begin{array}{c}23 \\
(74.19 \%)\end{array}$ & $\begin{array}{c}464 \\
(65.44 \%)\end{array}$ & $\begin{array}{c}119 \\
(67.23 \%)\end{array}$ & $\begin{array}{c}368 \\
(65.36 \%)\end{array}$ & $>0.05$ & $>0.05$ & $>0.05$ & $>0.05$ \\
\hline \multirow{3}{*}{$\begin{array}{c}\text { TSH } \\
\text { (n) }\end{array}$} & $\begin{array}{l}>22 \\
\mathrm{miu} / \mathrm{l}\end{array}$ & 28 & 136 & 8 & 156 & 6 & 158 & 40 & 124 & \multirow{3}{*}{$>0.05$} & \multirow{3}{*}{$>0.05$} & \multirow{3}{*}{$>0.05$} & \multirow{3}{*}{$>0.0$} \\
\hline & $\begin{array}{l}12-22 \\
\mathrm{miu} / \mathrm{l}\end{array}$ & 34 & 199 & 16 & 217 & 7 & 226 & 51 & 182 & & & & \\
\hline & $\begin{array}{l}<12 \\
\mathrm{miu} / \mathrm{l}\end{array}$ & 46 & 263 & 33 & 276 & 17 & 292 & 82 & 227 & & & & \\
\hline \multirow{3}{*}{$\begin{array}{c}\text { FT4 } \\
\text { (n) }\end{array}$} & $\begin{array}{l}>4.2 \\
\mathrm{pmol} / \mathrm{l}\end{array}$ & 32 & 184 & 24 & 192 & 11 & 205 & 59 & 157 & \multirow{3}{*}{$>0.05$} & \multirow{3}{*}{$>0.05$} & \multirow{3}{*}{$>0.05$} & \multirow{3}{*}{$>0.0$} \\
\hline & $\begin{array}{l}0.27-4.2 \\
\mathrm{pmol} / \mathrm{l}\end{array}$ & 57 & 319 & 27 & 349 & 16 & 360 & 87 & 289 & & & & \\
\hline & $\begin{array}{l}<0.27 \\
\mathrm{pmol} / \mathbf{l}\end{array}$ & 15 & 89 & 6 & 98 & 3 & 101 & 23 & 81 & & & & \\
\hline
\end{tabular}

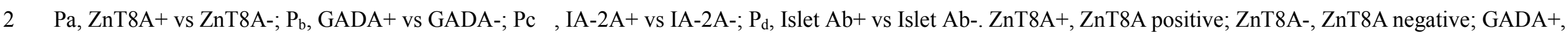
GADA positive; GADA-, GADA negative; IA-2A+, IA2A positive; IA-2A-, IA2A negative; Islet Ab+, at least one islet autoantibody positive; Islet Ab-, all islet autoantibodies negative. 
1 Additional File 1 The published studies investigated prevalence of islet autoantibodies in AITD patients.

\begin{tabular}{|c|c|c|c|c|c|c|c|c|}
\hline Study & Year & Ref. & Study population & $\begin{array}{l}\text { GADA (AITD/ } \\
\text { controls)(\%) }\end{array}$ & $\begin{array}{c}\text { ICA } \\
\text { (AITD/ } \\
\text { controls)(\%) }\end{array}$ & $\begin{array}{c}\text { IA2A } \\
\text { (AITD/ } \\
\text { controls)(\%) }\end{array}$ & $\begin{array}{c}\text { IAA } \\
\text { (AITD/ } \\
\text { controls)(\%) } \\
\end{array}$ & $\begin{array}{l}\text { ZnT8A } \\
\text { (AITD/ } \\
\text { controls)(\%) }\end{array}$ \\
\hline Pilia & 2011 & 25 & $\begin{array}{l}236 \text { non-diabetic Sardinian children and } \\
\text { adolescents with autoimmune thyroiditis; } \\
949 \text { healthy controls }\end{array}$ & $5.09 / 3.79$ & - & $3.39 / 1.16$ & - & \\
\hline Moriguchi & 2011 & 29 & $\begin{array}{l}866 \text { Japanese AITD patients (diabetics } \\
\text { included);282 controls }\end{array}$ & $5.8 / 2.1$ & - & - & - & \\
\hline Sallorenzo & 2017 & 31 & $\begin{array}{l}324 \text { AITD patients (non-diabetic } \\
\text { patients); } 93 \text { healthy controls }\end{array}$ & $4.9 / 0$ & - & $0.7 / 0$ & - & \\
\hline Maugendre & 1997 & 48 & $\begin{array}{c}600 \text { Caucasian patients with recently } \\
\text { diagnosed Graves' disease (10 diabetics } \\
\text { and } 590 \text { non-diabetics) }\end{array}$ & & 4.9 (non-diabetic) & & $\begin{array}{c}4 \\
\text { (non-diabetic) }\end{array}$ & \\
\hline Kawasaki & 1995 & 28 & 288 non-diabetic AITD patients; 235 controls & $6.3 / 0.9$ & $0 / 0$ & - & $3.8 / 0$ & \\
\hline Yamaguchi & 1991 & 17 & $\begin{array}{l}316 \text { AITD patients (T1DM included); } 53 \\
\text { T1DM patients; } 144 \text { healthy control subjects }\end{array}$ & & $7.6 / 0.7$ & & & \\
\hline $\mathrm{Ng}$ & 1990 & 19 & 97 non-diabetic AITD patients & - & 0 & - & 7.2 & \\
\hline Jonsdottir & 2019 & 33 & 278 patients with newly diagnosed GD & 8.7 & & 3.2 & & 7.6 \\
\hline Rydzewska & 2019 & 54 & $\begin{array}{l}44 \text { children with GD;65 children with HT;199 } \\
\text { children with T1DM with or without AITDs;58 } \\
\text { control children }\end{array}$ & $7.3 / 3.4$ & & $5.5 / 0$ & $3.7 / 0$ & $9.2 / 3.4$ \\
\hline
\end{tabular}

2 
Additional File 2 Clinical characteristics of type 1 diabetes mellitus with autoimmune thyroid disease(T1DM with AITD), autoimmune

2 thyroid diseases (AITD), non-autoimmune thyroid diseases (nAITD) and health control (HC) subjects.

\begin{tabular}{|c|c|c|c|c|c|c|c|c|}
\hline & \multicolumn{4}{|c|}{ Groups } & \multicolumn{4}{|c|}{ P Value } \\
\hline & $\begin{array}{c}\text { AITD } \\
(n=740)\end{array}$ & $\begin{array}{c}\text { T1DM with } \\
\text { AITD } \\
(n=108)\end{array}$ & $\begin{array}{c}\text { nAITD } \\
(n=172)\end{array}$ & $\begin{array}{c}\text { HC } \\
(n=115)\end{array}$ & $\mathbf{P}$ & $\mathbf{P a}_{\mathbf{a}}$ & $\mathbf{P}_{\mathbf{b}}$ & $P_{c}$ \\
\hline $\begin{array}{c}\text { sex } \\
\text { (female/male) }\end{array}$ & $600 / 140$ & $67 / 41$ & $141 / 31$ & $87 / 28$ & $<0.05^{*}$ & $<0.01^{*}$ & $>0.05^{*}$ & $>0.05^{*}$ \\
\hline $\begin{array}{c}\text { age } \\
\text { (years) }\end{array}$ & $40.4 \pm 14.0$ & $32.7 \pm 17.5$ & $50.3 \pm 13.7$ & $44.7 \pm 12.8$ & $<0.05 \dagger$ & $<0.01 \S$ & $<0.01 \S$ & $<0.01 \S$ \\
\hline $\begin{array}{l}\text { duration } \\
\text { (years) }\end{array}$ & $2.57 \pm 4.82$ & $0.89 \pm 2.55^{a}$ & $1.10 \pm 2.72$ & - & $<0.05 \ddagger$ & $<0.01 \S$ & $<0.01 \S$ & - \\
\hline $\begin{array}{c}\text { BMI } \\
\left(\mathrm{Kg} / \mathrm{m}^{2}\right)\end{array}$ & $22.44 \pm 3.23$ & $20.76 \pm 3.42$ & $23.50 \pm 3.40$ & $21.42 \pm 2.56$ & $<0.05 \ddagger$ & $<0.01 \S$ & $<0.01 \S$ & $<0.01 \S$ \\
\hline
\end{tabular}

$3 \mathrm{P}_{\mathrm{a}}$ : AITD vs T1DM with AITD, $\mathrm{P}_{\mathrm{b}}:$ AITD vs nAITD, $\mathrm{P}_{\mathrm{c}}$ : AITD vs $\mathrm{HC},{ }^{*} \mathrm{x}^{2}$ analysis, $\dagger$ ANOVA, $\ddagger$ Kruskal-Wallis test, $\S$

4 independent-samples T Test, ${ }^{a}$ represents the duration when T1DM and AITD co-exist. 
2 (T1DM with AITD), autoimmune thyroid diseases (AITD), non-autoimmune thyroid diseases (nAITD) and health control (HC)

3 subjects. ${ }^{*} \mathrm{P}<0.05, \mathrm{NS}$ : not significant.
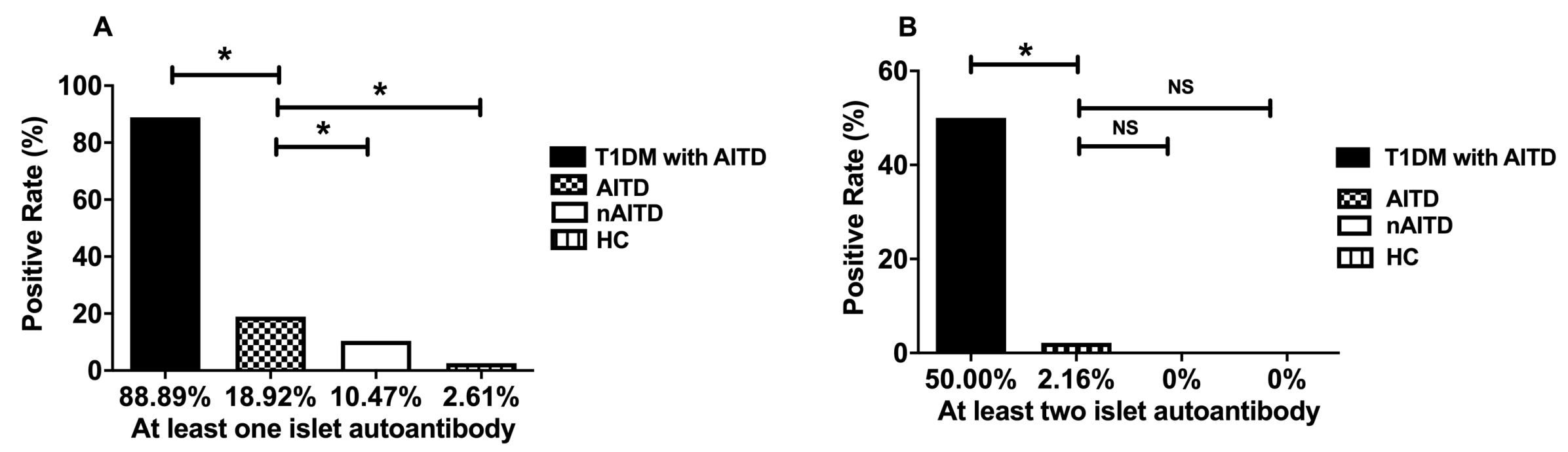
$2(\mathrm{HT})$ subjects. ${ }^{* *} \mathrm{P}<0.01, \mathrm{NS}$ : not significant.

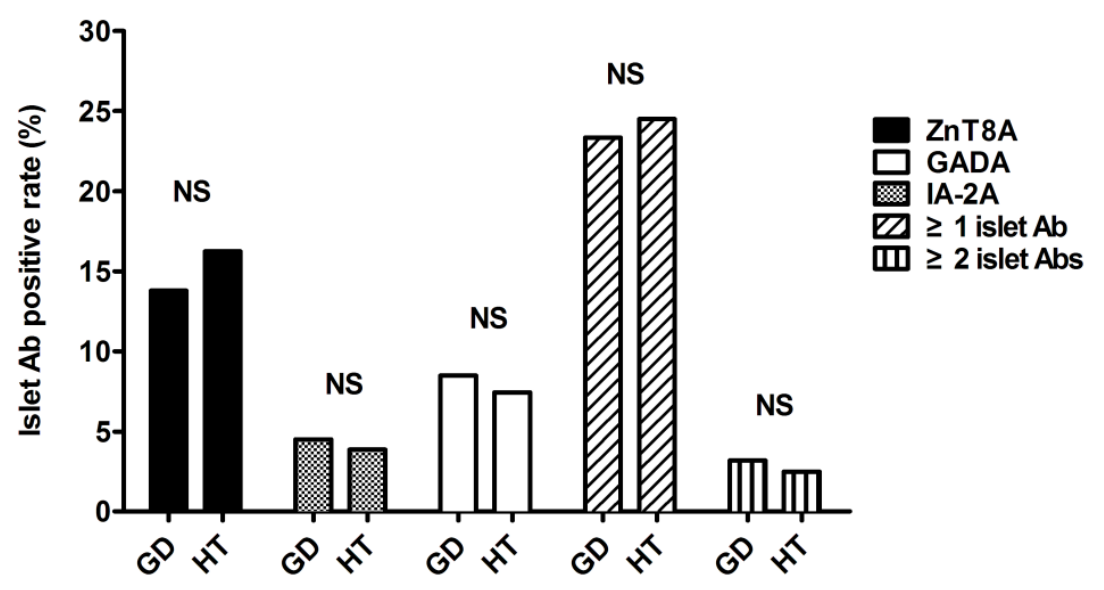

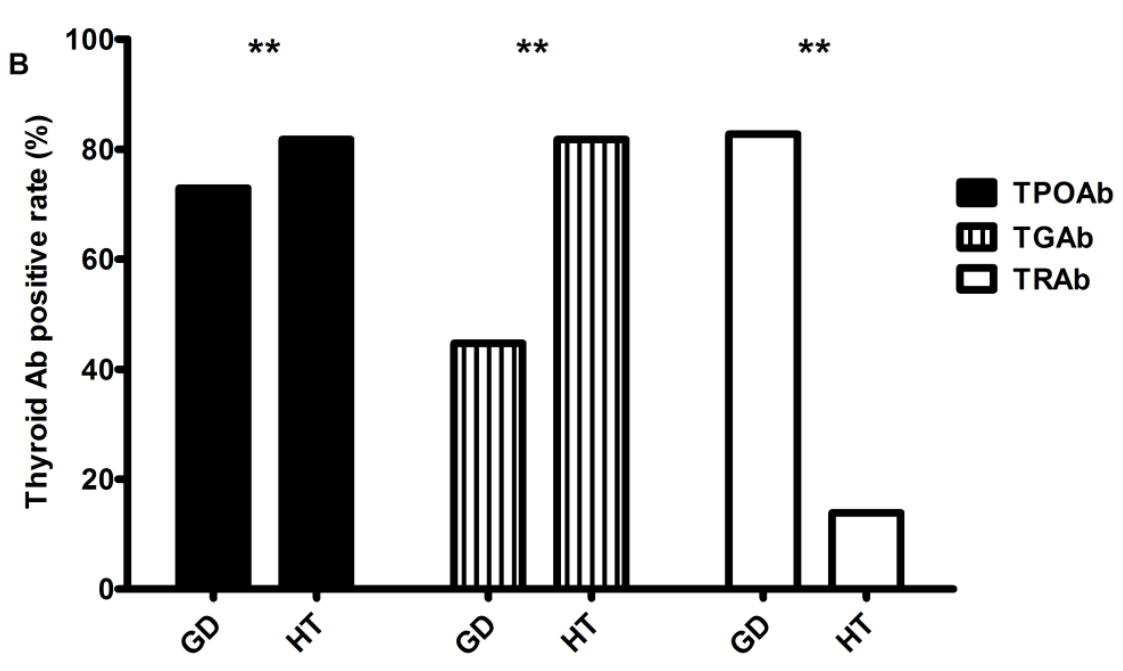


1 Additional File 5 Distributions of islet autoantibodies and thyroid autoantibodies in Graves' disease (GD) and Hashimoto's thyroiditis $2(\mathrm{HT})$ subjects.
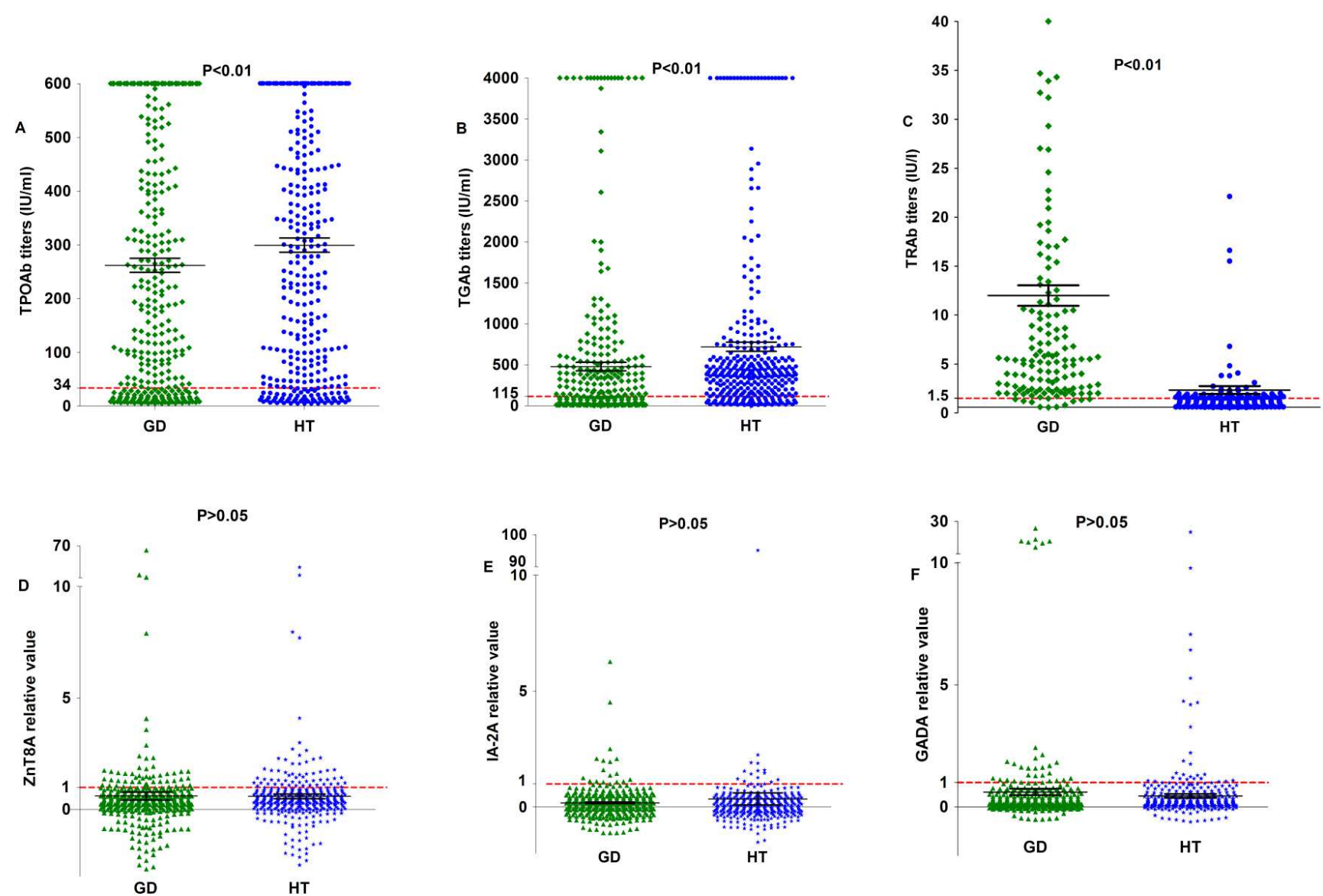
1 Additional File 6 Distribution of islet autoantibody relative values in TPOAb-positive AITD subjects with high-titer TPOAb(H-TPOAb)

2 and low-titer TPOAb(L-TPOAb).
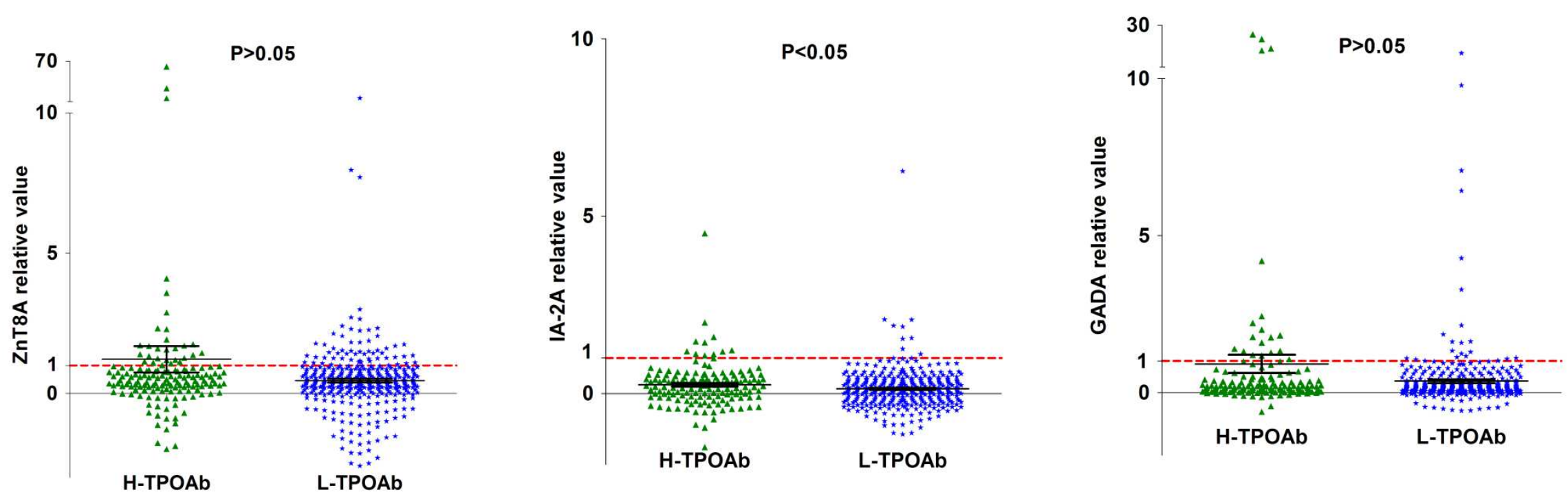
Additional File 7 Multivariable linear regression

\begin{tabular}{|c|c|c|c|c|}
\hline \multirow{2}{*}{ Independent variable } & \multicolumn{4}{|c|}{ Dependent variable } \\
\hline & $\beta$ & $P$ value & $\beta$ & $P$ value \\
\hline ZnT8A relative value & - & - & 0.183 & $<0.01$ \\
\hline GADA relative value & 0.352 & $<0.01$ & - & - \\
\hline Duration & -0.019 & $>0.05$ & -0.002 & $>0.05$ \\
\hline BMI & 0 & $>0.05$ & -0.031 & $>0.05$ \\
\hline FT3 & -0.018 & $>0.05$ & -0.015 & $>0.05$ \\
\hline FT4 & 0.017 & $>0.05$ & 0.013 & $>0.05$ \\
\hline TRAb & -0.001 & $>0.05$ & 0.001 & $>0.05$ \\
\hline
\end{tabular}




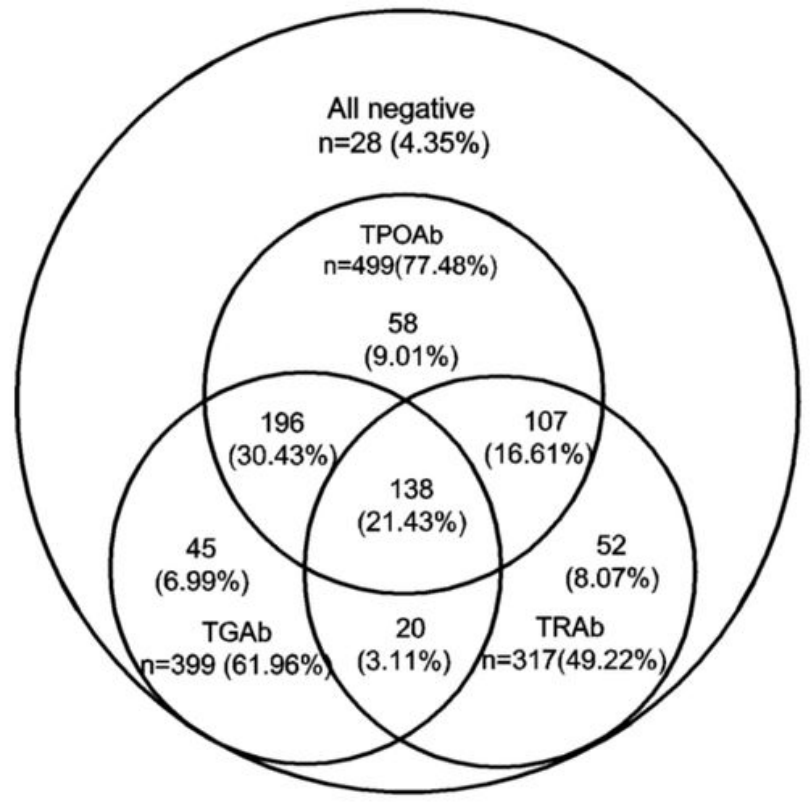

A

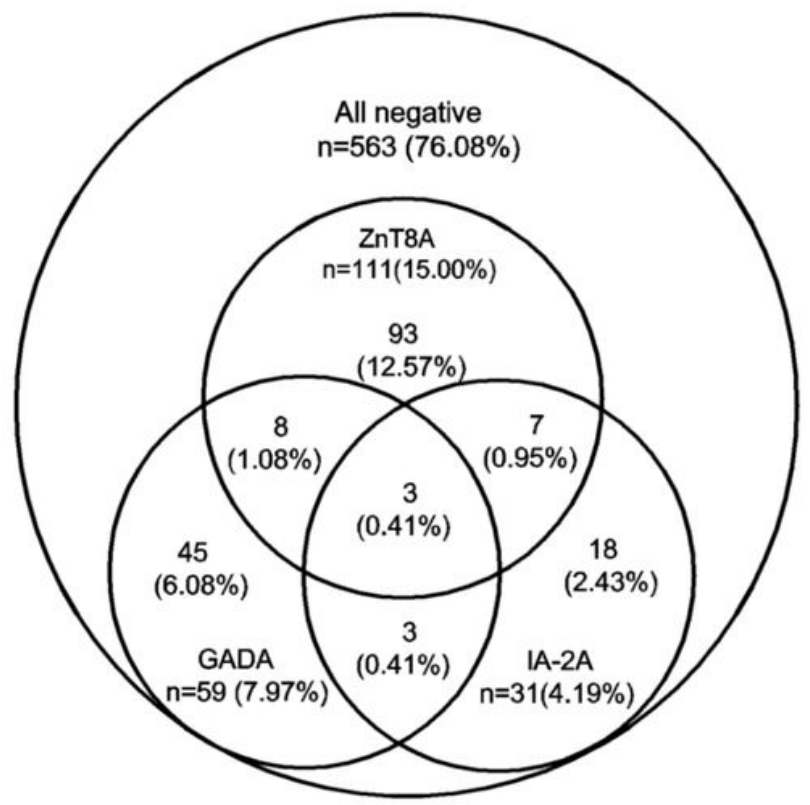

B

Figure 1

A. Frequency of thyroid autoantibodies is shown in 644 patients with autoimmune thyroid diseases. Of these, 616 (95.65\%) were positive for at least one thyroid autoantibody. B. Frequency of islet autoantibodies is shown in 740 patients with autoimmune thyroid diseases. Of these, $177(23.92 \%)$ were positive for at least one islet autoantibody 

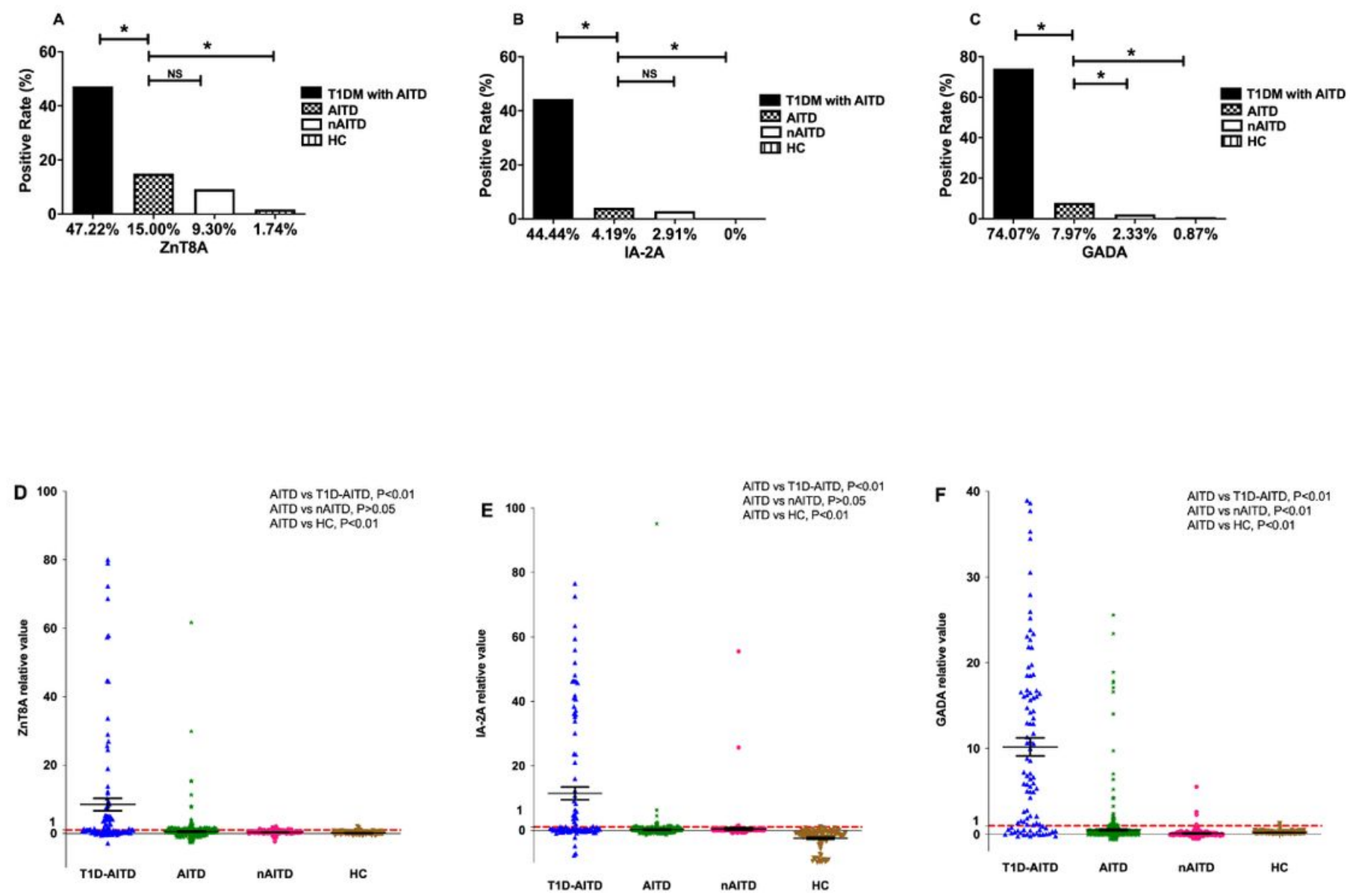

Figure 2

Frequency of islet autoantibodies in T1DM with AITD, AITD, nAITD and HC subjects. 

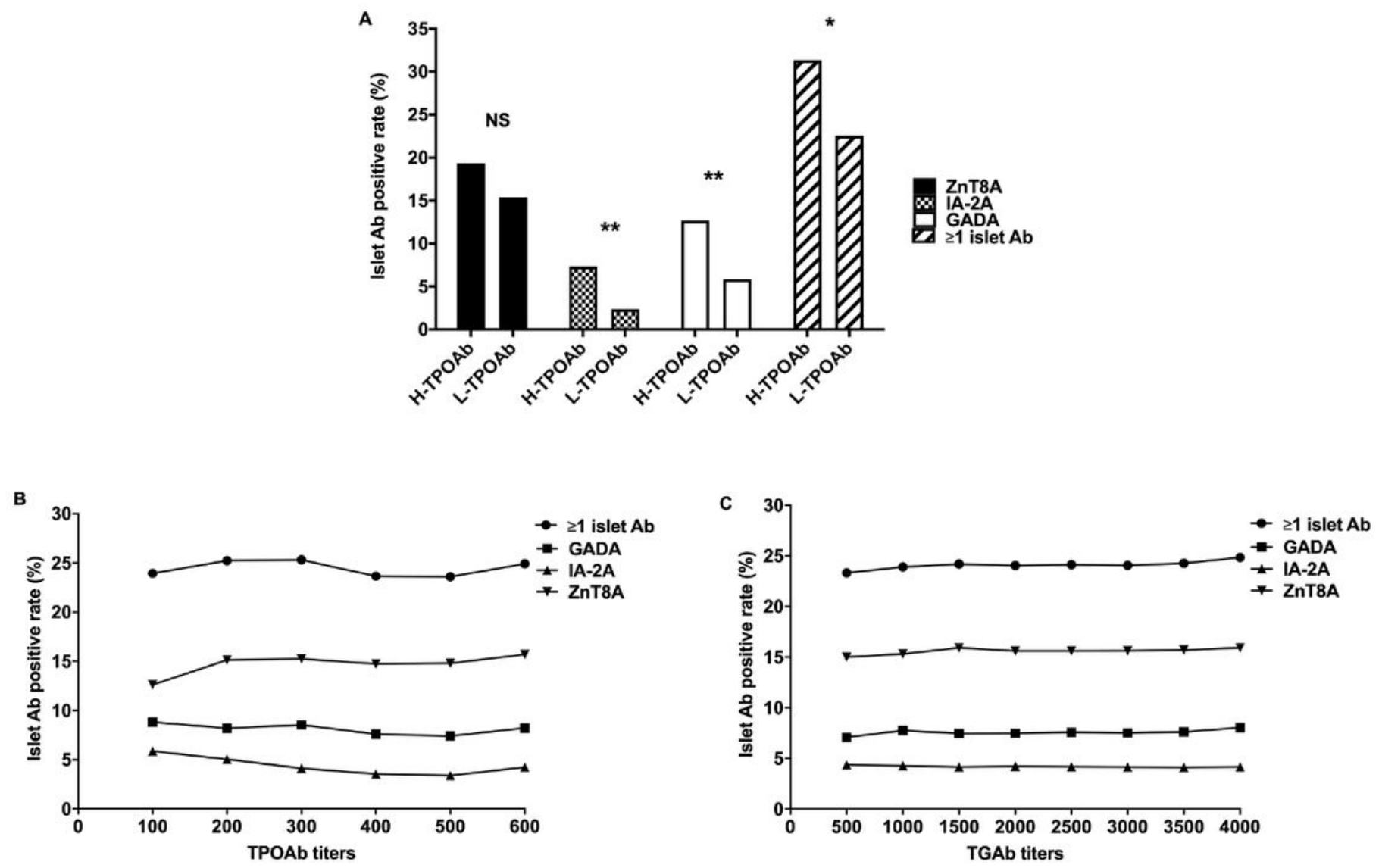

Figure 3

Frequency of islet autoantibodies in AITD subjects with high titer TPOAb and low titer TPOAb.

\section{Supplementary Files}

This is a list of supplementary files associated with this preprint. Click to download.

- AdditionalFile.pdf

- Table1.pdf 